Volume, 14, n.1, ano, 2018

\title{
INFÂNCIA E CIDADANIA EM CAROLINA DE JESUS E SANDRA MARA HERZER ${ }^{1}$
}

\author{
Elisângela da Silva Santos ${ }^{2}$ \\ Dayane Assis Nascimento ${ }^{3}$
}

Resumo: Esse artigo tem como objetivo analisar aspectos da chamada literatura marginal, bem como, perceber como a infância é apresentada nas obras de duas autoras: Carolina Maria de Jesus (19141977) e Sandra Mara Herzer (1962-1982), que escreveram respectivamente os livros Quarto de Despejo (1960) e A queda para o alto (1983). Trata-se de mulheres, escritoras, poetisas, pobres, marginalizadas, sem oportunidades para usufruir de uma educação formal de qualidade, e que não se conformaram com a realidade que as cercavam. Essas características conectam as histórias de vidas das autoras que retomamos neste texto, cuja temática nos possibilitou enfrentar alguns temas caros à sociedade brasileira, como por exemplo a pobreza, a violência e o racismo. Aqui realizamos um aprofundamento teórico sobre o conceito de Literatura Marginal e como a questão da cidadania, tão requerida pelas autoras, aparece nestas obras, além de apresentarmos a percepção das escritoras sobre a infância e a criança.

Palavras-chave: Carolina Maria de Jesus. Sandra Mara Herzer. Infância. Literatura Marginal.

\section{CHILDHOOD AND CITIZENSHIP IN CAROLINA DE JESUS AND SANDRA MARA HERZER WORKS}

Abstract: This article aims to analyze some aspects of the so-called marginal literature, as well as to understand how childhood is presented in the works of two authors: Carolina Maria de Jesus (1914-1977) and Sandra Mara Herzer (1962-1982), who wrote respectively the books Quarto de Despejo - "Lumber Room" (1960) and A queda para o alto - "Descending Upwards" (1983). This is about women, writers, poets, poor, marginalized, without opportunities to enjoy a formal education of quality, and who could not accept the reality that surrounded them. These characteristics connect the life histories of those authors, which we have resumed in this text and whose thematic enabled us to face some issues prized to Brazilian society, such as poverty, violence and racism. Here we carried out a theoretical background on the concept of Marginal Literature and how the question of citizenship, so required by those authors, appears in these works, as well to present the perception of those writers about childhood and the child.

Key-words: Carolina Maria de Jesus. Sandra Mara Herzer. Childhood. Marginal Literature.

\footnotetext{
${ }^{1}$ Este trabalho é resultado do projeto intitulado Infância e Literatura: uma análise sociológica, e foi tema da Iniciação Científica desenvolvida no Programa Institucional de Bolsas de Iniciação Científica da UFG entre 2015 e 2017 pela Graduada em Pedagogia Dayane Assis Nascimento e orientado pela professora Doutora Elisângela da Silva Santos.

${ }^{2}$ Doutora em Ciências Sociais pela Unesp/Marília, Professora Adjunta II da Universidade Federal de Goiás/Jataí, na área de Sociologia e Fundamentos.

${ }^{3}$ Graduada em Pedagogia pela Universidade Federal de Goiás/Pedagogia.
} 


\section{HUFFiraitus REF LEstloxis

Volume, 14, n.1, ano, 2018

Nós somos pobres, viemos para as margens do rio. As margens do rio são os lugares do lixo e dos marginais. Gente da favela é considerado marginais. (Carolina Maria de Jesus).

Aquele era um quartinho pequeno, sem condições de suportar a quantidade de menores detidos $e$, pouco a pouco, esse número aumentava, sendo que junto com as meninas ficavam as crianças, incluindo recém-nascidos. (Sandra Mara Herzer).

Carolina Maria de Jesus nasceu em Minas Gerais, na cidade de Sacramento, filha de pais analfabetos, chegou em São Paulo em 1947, foi catadora de material reciclável e viveu na favela do Canindé em São Paulo. Embora Carolina tenha frequentado a escola apenas até o segundo ano do primário, aprendeu a ler e a escrever, desenvolveu e cultivou o gosto pela leitura e o hábito de escrever, escrevia sobre seu dia-a-dia, numa espécie de diário, onde denunciava a realidade e as condições de vida na favela. Seus escritos revelam grande sensibilidade e talento para denunciar as condições adversas e injustiças sob as quais vivia. Estudos desenvolvidos pela pesquisadora Elena Pájaro Peres (2015), nos possibilita afirmar que, o primeiro ponto de formação da autora foi o seu avô, sendo que o mesmo tinha uma posição moral muito severa, severidade essa de origem na cultura afro-cristã; um segundo ponto de formação para Carolina foi o oficial de justiça Manoel Nogueira, que em todas as tardes, em frente uma farmácia em Sacramento, lia para os negros que não podiam ou que não sabiam ler, suas leituras variavam entre os jornais da época que traziam notícias da Segunda Guerra Mundial, os pensamentos de Rui Barbosa (1849-1923), de José do Patrocínio (18531905) e os poemas de Castro Alves (1847-1871), "Foi com ele que Carolina começou a exercitar seu pensamento crítico" afirma Peres (2015); um terceiro ponto foi os dois anos que ela passou no Colégio Allan Kardec onde aprendeu a ler e então passou a ler tudo que podia. Leituras de Luís de Camões (1524-1580) a folhetins fizeram com que ela tomasse gosto pela literatura.

No ano de 1958 o jornalista Audálio Dantas (1929-2018), então repórter da Folha da Noite, foi encarregado de ir até a favela do Canindé, em São Paulo, onde Carolina morava, para fazer uma reportagem sobre um parque infantil da prefeitura, quando chegou ao local se deparou com uma gritaria motivada por adultos. Segundo conta Dantas, no prefácio de Quarto de despejo, Carolina chega ao local mostrando que "tinha o que dizer", e se aproximou 


\section{Volume, 14, n.1, ano, 2018}

gritando: "Onde já se viu uma coisa dessas, uns homens grandes tomando brinquedo de criança! Deixe estar que eu vou botar vocês todos no meu livro!”. O jornalista se interessou, e foi até o seu barraco, onde se surpreendeu com aproximadamente vinte cadernos encardidos, escritos com letras grandes. Pediu para levar alguns exemplares para casa e se encantou com a leitura.

Após Carolina ser encontrada pelo jornalista Audálio Dantas, sua vida mudou completamente, pois, seus escritos, que para ela significava apenas relatos pessoais, foi visto pelo jornalista como uma narrativa, que de forma única denunciava o sofrimento do homem relegado à condição mais desesperada e desumana de vida.

Seus cadernos são organizados por Dantas em um só livro, sob o título Quarto de despejo. Em 1960 foi publicado, sendo que nos três primeiros dias após a publicação foram vendidos dez mil exemplares, esta obra teve uma enorme repercussão, foi traduzida em aproximadamente quatorze idiomas e foi distribuída em 40 países. Além deste, Carolina escreveu outros quatro livros: Casa de alvenaria (1961), Pedaços da fome (1963), Provérbios (1963) e Diário de Bitita (1982).

Sandra Mara Herzer ou Anderson Herzer como se autodenominou (1962-1982), nasceu no Paraná, na cidade de Rolândia. Foi escritora, poetisa e transgênero. Ficou órfã de pai e mãe muito cedo; tinha quatro anos quando seu pai foi assassinado num bar, sua mãe sem possibilidade de trabalho começou a se prostituir, contraiu doença venérea e faleceu antes que ela completasse oito anos. Após a morte de sua mãe a autora foi morar com a avó, de quem gostava muito, mas que também morreu pouco tempo depois. Nova mudança em sua vida, desta vez, para a cidade de São Paulo, foi morar com a tia casada com um homem mais velho, que abusou sexualmente de Sandra quando tinha apenas 14 anos

Já adolescente, ela saía à noite, tomava Coca-Cola com Optalidon (analgésico utilizado como calmante e sedativo), este foi o grande motivo encontrado pelos tios para colocá-la, sem que tivesse cometido qualquer crime, na FEBEM (Fundação Estadual para o Bem estar do Menor) instituição de nível estadual da FUNABEM (Fundação Nacional de Bem Estar do Menor), onde ficou interna dos 14 aos 17 anos.

Herzer direcionou, desde cedo, sua sensibilidade para uma poesia em busca de profundidade, em sua obra $A$ queda para o alto cujo formato é de uma pequena biografia, escrita aos 18 anos, publicada pela editora Vozes - que hoje está na $25^{\mathrm{a}}$ edição e traduções 


\section{Volume, 14, n.1, ano, 2018}

para outros idiomas - a poetisa conta como ficou durante toda a adolescência, presa nas instalações da FEBEM, vivendo entre fugas, castigos, torturas, amizades e amores. Fez dessa vida, no recinto da prisão cruel, destinada aos menores pobres e marginalizados uma intensa e original relação familiar, construída a duras penas com as demais companheiras, e lá encontrou a própria liberdade nas paixões amorosas, acompanhadas de sofrimentos e vitórias, como sendo a única existência possível.

Quando Herzer completou dezessete anos o ex-deputado estadual Eduardo Suplicy sensibilizado com seus poemas e sua história, atuando como seu responsável, lhe deu uma oportunidade de trabalho em seu gabinete e uma "vida livre", fora dos muros da instituição.

Em uma entrevista ao Promenino, Suplicy conta como chegou a conhecer a escritora e sua obra:

Recebi uma ligação da presidenta do Movimento em Defesa do Menor, Lia Junqueira. Fui visitá-la num dia em que teve licença para estar fora da Febem. [...]. Então, eu fui até o juiz, contei a ele que havia convidado a jovem para fazer um estágio comigo no meu gabinete. Inicialmente, ela ajudava a atender telefone, passar fax, todas essas rotinas de escritório. Também a levei a uma pensão em Pinheiros, onde passou a morar.[...]. Ela sabia escrever muito bem e ainda tinha a preocupação de que a Febem publicasse suas poesias sem a sua assinatura, como se fossem trabalhos coletivos. Por isso, eu disse: 'Escreva um livro de poesia. Vou te dar a tarefa de escrever a história da sua vida e, uma vez que você tiver completado o livro, vou apresentá-lo a uma editora'. Quando ela acabou de escrever o livro com os poemas e a história dela, eu o encaminhei para a Editora Vozes, onde a Rose Marie Muraro e o Leonardo Boff, que eram os responsáveis pela editora, gostaram muito e resolveram publicar. (SUPLICY, 2015, s/p).

No entanto Herzer desiste de viver dois meses antes de seu livro ser publicado, e se joga do viaduto 13 de maio, Suplicy relata os conflitos vividos pela autora, que de alguma forma podem ter contribuído para sua decisão de suicidar.

Carolina Maria de Jesus e Sandra Mara Herzer, duas mulheres pobres, sem acesso aos sistemas educacionais formais instituídos pela sociedade, fizeram da literatura uma forma para manifestar suas emoções e expressar suas visões de mundo, trazendo em seus relatos as vozes de tantas outras pessoas que vivenciavam as mesmas condições de vida relatadas por elas.

A luta por cidadania e pelo direito de escrever e ser reconhecidas como escritoras estão presentes nas obras de Carolina e Herzer, para que pudéssemos compreender o desafio dessas duas autoras marginais dedicamo-nos no primeiro tópico deste trabalho ao 
REVISTAELETRONICA

ItGFianius

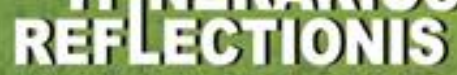

GRADUACCAO/POS-GRADUACAO EM EDUCAC AO

UFG/RE.

ISSSN 1807.9842

\section{Volume, 14, n.1, ano, 2018}

aprofundamento teórico sobre o conceito de Literatura Marginal e como a questão da cidadania, aparece nas obras, mas, além disso, definimos o conceito de Literatura Marginal, para problematizarmos o fato de que tais autoras, por não serem consideradas canônicas, foram estigmatizadas por muito tempo na literatura nacional.

No segundo tópico expomos sob a percepção da Sociologia da Infância como as infâncias são apresentadas nos livros Quarto de despejo e A queda para o alto, ressaltando a visão das escritoras sobre essa fase da vida, uma vez que direta e indiretamente, foi uma temática bastante recorrente em suas obras.

\section{A literatura "marginal" como expressão de uma cidadania}

O conceito de Literatura Marginal pode ser analisado como algo que está além de um estilo literário, pois, pode ser compreendido como um movimento da literatura contemporânea, conforme Vinícius Carneiro (2017), nos últimos anos, esta ideia está ligada a uma literatura produzida na periferia, e compreende como público, setores da sociedade brasileira que nunca foram alvo do mercado editorial. Para a problematização do conceito, nos detivemos às discussões realizadas por alguns autores, como Candido (1995), Soares (2008), Coronel (2014), entre outros.

De acordo com Zahidé Lupiaacci Muzart (1995), o estudo do cânone está ligado, pois, a vários aspectos, principalmente aquilo que é dominante numa determinada época: dominantes ideológicas, estilo de época, gênero dominante, geografia, sexo/sexualidade, raça, classe social e outros. Aquilo que, é canonizado em certas épocas, é esquecido noutras; o que foi esquecido numa, é resgatado em outra. Os textos de Herzer e de Jesus são exemplos de literaturas não canônicas, uma vez que se deparam com diversos impasses: ambas são mulheres, pobres, frequentaram parcialmente a escola formal, no caso de Herzer, expresidiária, sem sentimento de pertença à uma família nuclear, transgênera, abusada sexualmente; no de Carolina: mãe solteira, negra, favelada, todas características que impedem a definição de um espaço central ou dominante na sociedade, entretanto, o fato de não escreverem a partir do cânone não fazem de suas literaturas algo menor e nem pior, sim definem seus estilos que traduzem suas "condições humanas".

A partir da análise dos respectivos contextos históricos que as obras de Carolina Maria de Jesus (1914-1977) e de Sandra Mara Herzer (1962-1982) foram escritas, tivemos 


\section{Intreirainus RA;

\section{Volume, 14, n.1, ano, 2018}

condições de perceber que as autoras pesquisadas fizeram da literatura uma forma para manifestar suas emoções e expressar suas visões de mundo, trazendo em seus relatos as vozes de tantas outras pessoas que vivenciavam as mesmas condições de vida relatadas por elas.

Os escritores da Literatura Marginal recusam todos os modelos estéticos rigorosos e apresentam uma escrita espontânea com uma linguagem coloquial, ou seja, não se filiam a nenhuma tradição literária específica, no entanto, o tom da crítica e da denúncia, os aproxima dos movimentos do Realismo e do Naturalismo, esses autores possuem semelhante perfil social: são pessoas que vivem ou representam as periferias, vivenciam as condições relatadas em suas obras, e, de certa forma, representam essa população. Sobre esse aspecto Soares (2008) afirma que:

A expressão "literatura marginal", no que concerne a sua definição, está relacionada por um lado a escritores que se dizem à margem de algo, seja da sociedade, do mercado literário, do cânone; por outro as obras que, por motivos diversos, não se enquadram no perfil considerado padrão, ou seja, obras que fogem da estética literária e do conteúdo paradigmático em voga numa determinada época. (SOARES, 2008, p.85).

Tanto Carolina Maria de Jesus como Sandra Mara Herzer utilizaram a literatura para representar seus mundos de forma artística, ambas eram mulheres, poetisas, pobres, marginalizadas, sem oportunidades para acessar uma educação formal de qualidade, no entanto, não se conformaram com a realidade que as cercavam; ambas tinham grande sensibilidade e talento para denunciar as condições desumanas e injustiças sob as quais viviam e utilizaram da literatura para tal ofício.

Existe uma distância histórica entre as obras das autoras pesquisadas, Carolina foi uma das pioneiras da literatura marginal, a autora faz parte da "geração do mimeógrafo" ou dos chamados "grupos de autores malditos", Soares (2008) aponta que:

Nas décadas de 1960-1970, o termo marginal surgiu em virtude da resistência cultural que se firmava e alastrava no meio artístico, em especial no campo literário com grupos "concretistas" da "geração mimeógrafo" ou "grupo dos autores malditos" [...] recusavam a divulgação mercadológica formal, mas também viam suas obras rechaçadas pelo próprio mercado uma vez que os poemas, contos e romances que escreviam eram considerados de teor subversivos ou não passavam pelo critério de qualidade literária dos editores. (SOARES, 2008, p.85). 


\section{Hutianiaus

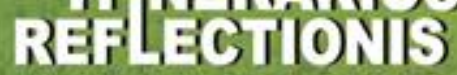

\section{Volume, 14, n.1, ano, 2018}

Já a Sandra Mara Herzer integra a literatura marginal contemporânea surgida a partir dos anos 90, cuja temática enfocada seria:

[...] Textos e obras que abordam o universo da criminalidade, da violência, do submundo das drogas e da miséria urbana, cujos autores são oriundos ou representam as periferias podem ser contemplados no interior desses critérios de marginalidade literária. Mas também poderiam ser incluídas nesse filão as obras contemporâneas produzidas por presidiários ou exdetentos, além dos textos surgidos durante o regime militar brasileiro e que deram origem ao termo. (SOARES, 2008, p.85).

Sandra Mara Herzer lança mão da literatura para refletir sobre sua vida e de tantas outras adolescentes que são vítimas das condições de vida dentro e fora da FEBEM, reflete sobre os danos ocasionados pelo uso de drogas, pela criminalidade, pela miséria e pelas diversas formas de violências sofridas durante sua vida.

No que diz respeito à literatura, desde as histórias infantis aos romances clássicos é possível notar estereótipos, visão preconceituosas e tratamentos jocosos e descomprometidos com pessoas que compõem o país, sendo que muitas vezes os grupos marginalizados nem sequer são mencionados ou representados de forma legítima. Diante dessa representação limitada da sociedade brasileira a chamada cultura popular e grande parte da população são esquecidas, menosprezadas, e deixadas às margens da sociedade. Essa hierarquização do meio reproduz apenas desigualdades em alta escala social.

O movimento da Literatura Marginal traz em seu conteúdo um apelo ao direito pleno à cidadania. Segundo Levine e Meihy:

[...] o começo da década de 1960 trazia uma "onda reformista" caracterizada pelo prenúncio de que as camadas pobres poderiam produzir figuras que levantariam a opinião pública, a literatura marginal fez parte dessa "onda reformista". (LEVINE e MEIHY apud MIRANDA, 2013, p.64).

Carolina Maria de Jesus e Sandra Mara Herzer chamaram atenção de grande parte do país e do mundo, através de seus relatos únicos de quem vivia na favela ou na periferia da cidade e tinham capacidade para expressar de forma literária as condições de pessoas que tinham sua cidadania negada, de quem sofria fome, violência, descaso por parte do estado, preconceitos e sobrevivia sob condições de vida desumanas.

As autoras em seus universos literários falam a partir de suas condições, suas narrativas estão fortemente ligadas ao espaço onde vivem, falam do lugar do marginalizado, 


\section{Volume, 14, n.1, ano, 2018}

escrevem com tom de acusação pelas condições que são impostas a viver, no entanto, deixam evidente em seus livros que poderiam mudar suas condições e lutaram por espaço, por serem vistas, acreditaram numa realidade mais justa e humana, não numa ficção, mas na realidade que se faz em cada humano e lutaram por isso através de suas obras. Encararam a realidade que as desafiavam a reconhecer direitos em cada um dos seres do mundo, alimentaram um processo de construção de convencimento permanente e aberto no qual havia lutas por serem feitas, resistências por serem construídas, agendas novas a serem pautadas e através da literatura viveram a luta de humanização da humanidade.

Em seu diário Carolina relata as dificuldades de viver na favela, de ser mãe e não contar com a ajuda dos pais de seus três filhos, da falta de alimento constante, da falta de dinheiro, das dores físicas ocasionadas por seu trabalho, da dificuldade de manter os filhos na escola e fora da criminalidade, do descaso dos governantes com os pobres e desempregados, a autora faz uma análise e crítica constante de seus problemas pessoais e também dos problemas sociais, seu discurso é peculiar porque ela fala partir da sua realidade, da sua posição de mulher, negra, pobre, mãe solteira, semiletrada, favelada e além de representar outras tantas mulheres que viviam na mesma condição que a dela também denunciou, contestou e se indignou diante da sua realidade:

15 de junho...Fui comprar carne, pão e sabão. Parei na banca de jornais. Li que uma senhora e três filhos havia suicidado por encontrar dificuldade de viver. [...] A mulher que suicidou-se não tinha alma de favelado, que quando tem fome recorre ao lixo, cata verduras nas feiras, pedem esmola e assim vão vivendo. [...] Pobre mulher! Quem sabe se de há muito ela vem pensando em eliminar-se, porque as mães tem muito dó dos filhos. Mas é uma vergonha para a nação. Uma pessoa matar-se porque passa fome. E a pior coisa para uma mãe é ouvir esta sinfonia: - Mamãe eu quero pão! Mamãe, eu estou com fome! (JESUS, 1993, p.56).

Herzer escreve com a mesma indignação e coragem, critica a assistência destinada aos menores na FEBEM, a superlotação da instituição, a falta de higiene, as torturas e violências sofridas pelas internas, e também discorre sobre as tristezas vividas no âmbito familiar para explicar os motivos que a levaram a ser internada na FEBEM como, por exemplo, a perda dos pais:

Me recordo de meu pai, a única lembrança que trago dele é a imagem de uma cena que sempre recordo... eu e minha irmã, em cima de duas cadeiras, ajoelhadas, olhando o corpo de meu pai em seu caixão. [...] Eu, brincando ao 


\section{Intreirainus RB;

\section{Volume, 14, n.1, ano, 2018}

redor de algumas cadeiras, ouvi a conversa. Elas contaram que estavam voltando de São Paulo, onde assistiram o enterro de minha mãe, Lurdes Peruzzo. [...] Fiquei triste, com vontade de chorar, apesar de tudo. No momento exato, não tive meios para me mover, mas, de repente, pensei em um modo de fugir daqueles comentários. Andei em direção aos fundos da casa, onde tinha uma pequena horta. Foi lá que eu chorei, sem que ninguém visse, de cabeça baixa, fingindo que estava colhendo abobrinhas. (HERZER, 1982, p. 24-25).

Nas primeiras páginas do seu livro Herzer faz um pequeno resumo de sua vida começando da pequena infância até sua internação na FEBEM, aos 14 anos, a autora realiza essa retrospectiva com o objetivo de que o leitor compreenda os diversos fatores pelos quais ela chegou a ser internada, relata a tristeza que sentia ao perder pai e mãe tão cedo, e logo depois da morte dos pais perder também a avó, a quem demonstra que tanto amava. A autora também relata o quão doloroso foi sofrer abuso sexual do tio que era considerado por ela como um pai:

Talvez meu pai já pensasse em fazer isso antes, ou talvez tenha sido algo que ele pensou naquele momento, mas estava eu tapando alguns vidros de perfume, quando senti seu corpo tocar no meu corpo, e suas mãos me apertarem, aquelas mãos que antes eram tão dóceis e tão paternas, tornaramse imundas e nojentas. Sim, meu pai me desejava. Eu me virei contra ele, estupidamente, tentando afastá-lo de mim. (HERZER, 1982, p.41).

No final do breve relato sobre alguns acontecimentos de sua vida Herzer justifica o porquê de resumir o que havia sucedido até a sua internação:

Esse foi o motivo de desentendimento entre mim e meus pais, foi mais ou menos o que se pode chamar de "porquê" da minha vida, que não era mais vivida dentro de casa; e o fato de que eu bebia, saía às noites e retornava só na madrugada foi como a gota d'água que estava faltando para que minha liberdade fosse apreendida durante três anos na FEBEM. (HERZER, 1982, p.42).

A literatura marginal pode ser entendida como mais que um movimento literário, mais que um dado sócio histórico, como dissemos, mais que um aspecto de uma "onda reformista", as obras produzidas por autores marginais, são também como uma peça central em uma luta política, uma luta por igualdade, por direitos, uma luta contra a fome, contra a violência. A literatura marginal é um lugar de luta e é travado em âmbito literário uma luta por humanização, nesse sentido Antonio Candido (1995) contribui ao destacar que ele entende por humanização: 


\section{InTFianius RA;

\section{Volume, 14, n.1, ano, 2018}

$\mathrm{O}$ processo que confirma no homem aqueles traços que reputamos essenciais, como o exercício da reflexão, a aquisição do saber, a boa disposição para com o próximo, o afinamento das emoções, a capacidade de penetrar nos problemas da vida, o senso de beleza, a percepção da complexidade do mundo e dos seres, o cultivo do humor. A literatura desenvolve em nós a quota de humanidade na medida em que nos torna mais compreensivos e abertos para a natureza, a sociedade, o semelhante (CANDIDO, 1995, p.182).

As obras de Carolina e de Herzer acompanham os acontecimentos do mundo de acordo com suas épocas, a literatura foi utilizada por elas para representar o que viam. As obras trazem muitas tonalidades pessoais e não apenas um caráter de representação social, através de seus livros elas buscavam resgatar os seus direitos à cidadania, escrever era uma alternativa para que elas pudessem sair da dura realidade de suas rotinas, para ir ao encontro da beleza e da fantasia, fazendo-as respirar de novo e repor suas energias garantindo-as o bem-estar e o equilíbrio físico e mental. Herzer expõe esses sentimentos de felicidade ao saber que conseguirá publicar um livro:

Naquele domingo eu não me cabia em felicidade. Voltei a FEBEM somente no final da tarde, com ideias e mais ideias de como iniciar este livro. A tentativa de ter um sonho realizado. Hoje sinto que logo muitos terão nas mãos uma estória verídica, sofrida, e tão esquecida pelos homens. (HERZER, 1982, p.135).

Produzir literatura, seja ela qual for, abrange a habilidade em usar o cérebro para alterar, renovar, recombinar os aspectos da vida, da experiência acumulada. Implica em sentir o mundo com vitalidade e fazer um novo uso do que se percebeu. A literatura possibilitou Herzer e Carolina expressarem suas vivências e resinificarem o que haviam percebido a partir de acontecimentos de suas vidas.

Segundo Candido (1995), a literatura é um dos direitos humanos indispensáveis ao ser humano, justamente pela capacidade de possibilitar o pleno desenvolvimento do imaginário, o autor aponta que "[...] toda obra literária é antes de mais nada uma espécie de objeto, objeto construído, e é grande o poder humanizador dessa construção, enquanto construção". (CANDIDO, 1995, p.179), é e exatamente essa a função da literatura na vida de Carolina e Herzer, elas usam a arte para dar uma humanidade ao duro cotidiano.

Ao negro, a mulher, ao semiletrado, ao marginal em uma sociedade que ignora e excluem as classes pobres são negados muitos direitos básicos como a saúde, a moradia, o 


\section{Volume, 14, n.1, ano, 2018}

trabalho e o acesso as diversas formas de arte, como por exemplo, o acesso a literatura e com isso o silêncio é imposto a esses grupos subalternos, no entanto, a partir dos anos 1960 uma luta vem sendo travada por meio de movimentos artísticos por parte desses grupos com o objetivo de conseguir espaço para uma auto representação, Carvalhal (2014) aponta que:

O reconhecimento das elaborações da margem, enquanto produção discursiva realizada a partir de contextos marcados pela narrativa musical e literária como objetos de cultura (nas suas distintas formas de expressão estética) e dos esforços para a consagração de carreiras, obras e movimentos culturais, como legítimos e relevantes objetos de estudo tem o mérito de privilegiar uma produção não canônica naquilo que ela tem de força irreprimível, inovadora, reconfiguradora, constituída a partir de sucessivos silenciamentos e fragmentações, rupturas e desvinculações a cada passo percorrido em direção ao reconhecimento, com suas estratégias de luta e afirmação de lugares não hegemônicos. (CARVALHAL, 2014, p.1).

Nas últimas páginas da segunda edição do livro Quarto de despejo (1993) foi disponibilizada uma entrevista com Carolina, em certa parte da entrevista o repórter questiona se ela sendo pobre e desprotegida não tinha medo de fazer as denúncias e acusações políticas e a autora responde:

Eu era revoltada, não acreditava em ninguém. Odiava os políticos e os patrões, porque o meu sonho era escrever e o pobre não pode ter ideal nobre. Eu sabia que ia angariar inimigos, porque ninguém está habituado a esse tipo de literatura. Seja o que Deus quiser. Eu escrevi a realidade. (JESUS, 1993, p.173).

Com Sandra não foi diferente, muitas foram as dificuldades encontradas para que pudesse escrever e publicar sua obra, ela relata um trecho comovente em que o diretor da FEBEM rouba seus poemas na intenção de publicar um livro:

Consegui com o Sr. Humberto uma saída da unidade para ir até o SENAI, mas infelizmente não foi possível para aquele dia. Portanto, minha saída foi adiada, isto porque tive uma discussão com o Sr. Humberto, porque pedi para que ele devolvesse minhas poesias as quais ele havia pego, dizendo publicar um livro em meu nome. Mas quando vi o esboço da capa, o sangue fervia nas minhas veias pois ele me disse que não seria possível lançar um livro com meu nome enquanto eu permanecesse na FEBEM. Portanto, seria publicado em nome da FEBEM com o título: "Os menores escrevem". (HERZER, 1982, p.132).

Mesmo que as obras de Carolina e Herzer apresentem uma reflexão sobre o lugar de fala e uma autoconsciência autoral importantíssima não são consideradas literatura pela crítica 


\section{Hetraiainus REF LEctilonis \\ REVISTAELETRONICA \\ GRADUACSAO/POS. GRADUACAO EM EDUCACSAO \\ UFG/REJ}

ISSN 1807.9892

\section{Volume, 14, n.1, ano, 2018}

literária. A pesquisadora Germana Pereira Henriques (2012) deixa uma questão aberta que pode ser o caminho para uma reflexão esclarecedora para se pensar como se define o que é e o que não é literatura "será que a literatura pode ainda ser definida pela escrita bonita?".

\section{A infância para além das instituições formais:}

Não é possível analisar e compreender infância e criança somente pelo viés da educação formal, e partindo apenas da criança escolarizada, pois, há diversas formas de tratar a criança e viver o período da infância, essas obras foram escolhidas para análise porque nelas são representadas infâncias de crianças marginalizadas e inseridas diferentes contextos e instituições educacionais, além de dilemas enfrentados pela sociedade brasileira como, por exemplo, racismo, violência, fome, miséria, desemprego.

Diante da complexidade do fenômeno da infância é complicado pensar em criança sem fazer uma analogia com o termo infância, criou-se uma relação um ponto de semelhança entre os dois termos (criança e infância). Entretanto, criança existe em toda e qualquer sociedade, já a infância é uma construção histórica das sociedades ocidentais.

Se pensarmos a infância como um período ou uma fase biológica, vamos ter certeza de que ela sempre existiu. Mas, e se pensamos no "sentimento de infância", será que ele sempre existiu? Será que ele sempre foi como é hoje? A infância sempre teve um espaço central na família?

Mary Del Priore (1999), ressalta de modo bastante interessante as diversas possibilidades de "enxergar" a criança:

As crianças brasileiras estão em toda parte. Nas ruas, na saída das escolas, nas praças, nas praias. Sabemos que seu destino é variado. Há aquelas que estudam, as que trabalham, as que cheiram cola, as que brincam, as que roubam. Há aquelas que são amadas e outras, simplesmente usadas. Seus rostinhos mulatos, negros, mestiços enfim, desfilam na televisão, nos anúncios da mídia, nos rótulos dos mais variados gêneros de consumo. (PRIORE, 1999, p. 08).

Deste modo, apostamos na ideia de que se as crianças brasileiras estão em toda parte, e integram mundos diversos, também podemos analisá-las sob o filtro da diversidade temática que as Ciências Sociais podem fornecer. O lugar da criança na sociedade brasileira nem sempre foi o mesmo, e refletir sobre isso numa sociedade desigual cujas grandes marcas 


\section{Volume, 14, n.1, ano, 2018}

históricas foram a escravidão e o colonialismo, pode nos auxiliar a percebê-la também como participante ativo em contextos específicos. Neste caso, os contextos se localizam nas obras de Carolina Maria de Jesus e de Sandra Mara Herzer, autoras que a partir de suas obras, trouxeram algumas contribuições para se pensar as crianças a partir de uma percepção que transcende os espaços institucionalizados mais comuns, como por exemplo a escola formal.

Durante o período em que a obra de Maria Carolina de Jesus estava sendo escrita, o Brasil passava por um momento de transição. Durante a leitura de todo o livro é possível notar que a autora estava vivendo sob as consequências ocasionadas por diversos fatores históricos, sendo estes de natureza econômica, política, social e que de forma significativa marcaram o período, a história do país e das pessoas que vivenciaram este momento.

A trajetória da Carolina Maria de Jesus no seu dia-a-dia, em sua busca por trabalho, na luta pela sobrevivência é sem dúvida uma representação da realidade de centenas de pessoas que vinham para os grandes centros urbanos em busca de trabalho e melhores condições de vida, trabalhando como catadora de lixo pelas ruas de São Paulo, Carolina relata em seu diário com muita propriedade a dura realidade que foi a peleja para conseguir se alimentar e alimentar os filhos:

30 de maio. Peguei a Vera e saímos. Ia pensando, será que Deus vai ter pena de mim? Será que eu arranjo dinheiro hoje? Será que Deus sabe que existe as favelas e que os favelados passam fome? (JESUS, 1993, p. 42)

O pensamento de Carolina, no que diz respeito, a colaboração dos adultos com atitudes de mau exemplo e a falta de moral para corromper a formação das crianças vai de encontro com o que os juristas do período diziam para explicar a grande quantidade de crianças infratores na cidade de São Paulo. Conforme Londoño (1998), nos anos de 1920 surgiu o conceito de menor, que neste momento era os herdeiros daquelas famílias "corrompidas" pelo vício e que minavam "a ordem moral da sociedade". (LONDOÑO, 1998, p. 137).

A autora era inconformada com as cenas que os filhos presenciavam, o que nos possibilita afirmar que, ela acreditava que as crianças eram observadoras e capazes ler e interpretar a realidade que as cercavam e que todos os "maus exemplos" vivenciados por seus filhos poderiam corromper suas personalidades, ou seja, ela tinha a ideia de que toda a 


\section{Volume, 14, n.1, ano, 2018}

educação fornecida por ela poderia ser anulada pela divergência entre sua fala e os exemplos vistos por eles.

Anete Abramowicz (2011), analisa o processo de autoria social da criança, afirma que no período da infância muitos aspectos são inscritos em suas histórias por influenciado meio social onde vivencia suas experiências, no entanto, ressalta que a criança também é singular e única; Carolina mesmo que de forma indireta reconhece a questão de que por meio da educação formal e não formal (oferecida pela escola e pela família, pela religião, no convívio com os vizinhos, nas brincadeiras com outras crianças e etc.), das condições socioculturais e econômicas se inscrevem muitas coisas nas crianças, e a todo o momento se sente responsável pela tarefa de inscrever aspectos moral na personalidade dos filhos, a autora possui uma visão de respeito com para com as crianças:

18 de julho de 1955 . Veio a D. Silvia reclamar contra os meus filhos. Que os meus filhos são mal iducados. Mas eu não encontro defeito nas crianças. Nem nos meus nem nos dela. Sei que criança não nasce com senso. Quando falo com uma criança the dirijo palavras agradáveis. [...]Sei dominar meus impulsos. Tenho apenas dois anos de grupo escolar, mas procurei formar o meu caráter. (JESUS, 1993, p. 13).

Por meio dos relatos de Carolina, percebemos que a autora tinha ideia de que um autêntico desenvolvimento só poderia ser completo se incluir a educação moral e que por falta da moralidade, multiplicam-se os cenários contrários ao bom desenvolvimento da sociedade. A escritora não tinha tempo e condições para dedicar-se ao lar e a educação dos filhos, ela nem sequer considerava o barraco onde morava um lar, o alimento era uma preocupação constante, o barulho da comida fritando na panela soava como música aos seus ouvidos, no entanto ela tinha uma ideia de lar ideal: "20 de julho de 1955. Refleti: preciso ser tolerante com os meus filhos. Eles não têm ninguém no mundo a não ser eu. Como é pungente a condição de mulher sozinha sem um homem no lar”. (JESUS, 1993, p. 19).

A autora acreditava que a educação escolar (formal) poderia oferecer melhores oportunidades, ascensão social e desejava que os filhos não tivesse a mesma sorte que ela, que no futuro eles tivessem uma vida digna, porque para Carolina não existia dignidade na vida do favelado, no entanto, ela não atribuía a responsabilidade da educação moral das crianças à escola, tinha consciência de que a interação com meio social em que os filhos estavam inseridos também os educavam. 


\section{Volume, 14, n.1, ano, 2018}

Ainda que Carolina se desdobrasse para garantir o alimento, a educação moral e formal dos filhos sentia as dificuldades de exercer o papel de mãe e pai, em alguns momentos ela mencionava as dificuldades que uma mulher sem homem enfrentava, mas também tinha revolta contra o sexo masculino:

19 de julho de 1955. Há casa tem cinco filhos e a velha é quem anda o dia inteiro pedindo esmolas. Há as que os esposos adoece e elas no penado da enfermidade mantem o lar. Os esposos quando vê as esposas manter o lar, não saram nunca mais. (JESUS, 1993, p. 35).

A família é considerada uma instituição muito importante da sociedade ocidental, no que diz respeito, a educação das crianças e na formação para o exercício da cidadania, ela é percebida como lugar afetivo e de relações indispensáveis à socialização dos indivíduos, que assim desenvolvem o sentido de pertencimento de um campo relacional impulsor de relações includentes na própria vida em sociedade.

Entretanto, esta instituição tem sofrido grandes mudanças em sua organização ao longo do tempo, sendo a sociedade dinâmica e estando em constante transformação, assim também é a estrutura familiar, que não é estática e sente os impactos desta mudança da sociedade.

Frente a estas novas mudanças, a estrutura familiar monoparental - família formada por um só chefe de família - vem crescendo substancialmente em nossa sociedade, mediante aos acontecimentos da vida Carolina tinha uma estrutura familiar monoparental, ficou sozinha no cuidado dos filhos.

Jacquet (2009), em um estudo que tem como objetivo, evidenciar a especificidade da socialização familiar, nas famílias recompostas após divorcio ou separação, aponta algumas abordagens desenvolvidas no campo das Ciências Sociais para compreender a origem das práticas educativas familiares. A primeira abordagem analisada pelo autor defende que a classe social a qual os pais pertence é o princípio explicativo básico, o referido autor cita Bernstein, para exemplificar essa ideia "[...] com certeza, do ponto de vista sociológico, é a classe social que determina mais profundamente as formas de socialização" (JACQUET, 2009, p. 312), sendo que com essa visão reforça que as famílias de classe média realizam uma educação com foco na autonomia, na liberdade e no respeito para com a criança, já a classe operária seria aquela que trata a criança com autoridade e rigor. Essa abordagem vai à contramão com todos os aspectos da educação que Carolina proporcionava aos filhos, mesmo 


\section{Volume, 14, n.1, ano, 2018}

a autora pertencendo à classe social pobre, não tendo uma família tradicional, demonstrava respeito para com as crianças e preocupação em formá-los para exercer cidadania de forma honesta e viver com autonomia.

Carolina mostra-se uma mulher educada e que se preocupava com a educação de seus filhos; embora não tenha estudado muito, relata que se preocupou em formar seu caráter, ser uma pessoa de bem:

Eu nada tenho que dizer de minha saudosa mãe. Ela era muito boa. Queria que eu estudasse para professora. Foi as condições da vida que lhe impossibilitou concretizar o seu sonho. Mas ela formou o meu caráter, ensinando-me a gostar dos humildes e dos fracos. (JESUS, 1993, p. 43-44).

No entanto, explicar as práticas educativas exclusivamente por meio da classe social a qual os pais pertencem é uma análise preconceituosa, pois relacionam pobreza, com falta de capacidade e valores, é como se toda a classe operária não possuísse valores e educação para socializar os filhos da forma esperada pela sociedade e tão pouco transmitir a moral para as crianças. No caso de Carolina, fica bastante explícito que a educação não formal foi uma das formas de acesso a conhecimentos e condutas não menos importantes e interessantes daqueles aprendidos nos bancos escolares.

No que se refere ao campo da Sociologia da Educação, Agnès Van-Zanten (1998), afirma que os elos sociais entre as famílias e a instituição escolar sempre tiveram no centro das preocupações da área, porém muitos sociólogos, especificamente nos anos 1960, realizaram análises macroscópicas e estatísticas entre posição social dos pais e a performance escolar dos filhos, desprezando os processos e as dinâmicas intrafamiliares, as práticas socializadoras e as estratégias educativas internas ao microcosmo familiar.

Neste sentido, a própria concepção de grupo familiar sofre uma inflexão, sem ignorar o peso dos condicionantes externos, deixa-se de concebê-los como mero reflexo da classe social, para perceber nele um sistema de ação, portador de um projeto autônomo e resultante de uma dinâmica normativa interna. Segundo Nogueira (1998), vista dessa forma, o funcionamento e as orientações familiares operariam como uma mediação entre, de um lado, a posição da família na estratificação social e, de outro, as aspirações e condutas educativas, e as relações com a escolaridade dos filhos.

Da mesma maneira que a mãe de Carolina aspirava que a filha se tornasse professora, Carolina também teve esta aspiração, tanto que a filha mais nova, Vera Eunice, se tornou uma 


\section{Volume, 14, n.1, ano, 2018}

professora. Além disso, constantemente a autora narra sua preocupação em levar sempre seus filhos à escola, em busca de um futuro diferente. Numa das passagens em que Carolina relata uma discussão com a vizinha, que a critica por não bater em seus filhos ela narra: "Não sou dada a violência. O José Carlos disse: - Não fique triste mamãe! Nossa Senhora Aparecida há de ter dó da senhora. Quando crescer eu compro uma casa de tijolos para a senhora". (JESUS, 1993, p. 14).

Nesse sentido, é válido retomar a ideia da Sociologia da Infância produzida na atualidade, que transcende a análise da educação das crianças para fora dos bancos escolares, e a visão de Carolina dialoga muito com a ideia dessa área de estudos, pois, mesmo Carolina primando pelo acesso dos filhos à educação formal não desconhece que a educação das crianças acontece em todos os lugares, na igreja, nas brincadeiras com as outras crianças, na convivência com as pessoas da favela, através do contexto social que as cercavam, Carolina chega a mencionar que a fome também ensina.

A voz de Sandra Mara Herzer surge como denúncia e ilustra de forma singular e com a sensibilidade de quem vivenciou a atrocidades cometidas contra os menores marginalizados dentro da instituição FEBEM, a começar pelo fato de que eram todos tratados sem distinção nenhuma:

A FEBEM cuida de menores infratores, menores deficientes, menores abandonados, menores que são recolhidos tarde da noite nas ruas; no final é verdade que não se consiga fazer nada por nenhum deles, pois essa mistura de pessoas transforma todos num só grupo, e não em grupos de deficientes, de abandonados, de menores trazidos das ruas, apenas grupos de menores $\mathrm{m}$ a r g i n a 1 i z a d o s (HERZER, 1983, p.52).

Herzer tem um senso de diversidade bastante avançado, não concorda com a uniformidade com que as detentas são tratadas, e nesse sentido vale ressaltar que as FEBEMs foram criadas com a proposta de lidar com os diversos históricos de vidados menores que ali chegassem. Kosminsky (1993), afirma que:

As unidades pertencentes à FEBEM/SP são de três tipos: Recepção, Triagem e Educacional. O menor é encaminhado para essas unidades de acordo com a categorização estabelecida pela FEBEM (abandonado, carente e infrator) e, ainda, segundo suas características pessoais (sexo e idade). (KOSMINSKY, 1993, p.157). 


\section{Hutianiaus

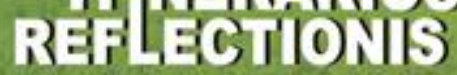

\section{Volume, 14, n.1, ano, 2018}

A crítica de Herzer vai ao encontro com a falta de diferenciação no trato com os diversos perfis existentes na unidade, sendo que essa diferenciação ficou apenas no projeto de defesa ao menor, na prática eram todos tratados como infratores, delinquentes, ladrões, no trecho citado a seguir, fica evidente a forma indiscriminada com que as crianças eram tratadas, chega a ser uma atrocidade:

Enquanto estive na FEBEM, outro fato muito desagradável, mas que éramos obrigados a ver sem nada poder fazer ou opinar: Menores completamente sãs enviadas ao sanatório. Sei que se torna difícil acreditar que um órgão, especializado em regenerar menores, tentar fazê-los ver a vida e as circunstâncias das coisas ruins, enfim, um local que, pelo nome, dá apoio e segurança ao menor, possa fazer tal coisa. Mas, infelizmente, confirma-se o ditado: "Um livro não se reconhece pela capa". (HERZER, 1983, p. 89).

O projeto do governo militar não se diferenciava tanto da política econômica de JK, na década de 1950. O que mudava era a estabilidade política conseguida pela repressão à oposição de esquerda, necessária para garantir a segurança ao investimento estrangeiro. Perez e Passone (2010) afirmam que,

Paralelamente, o arcabouço institucional e organizacional das políticas sociais se consolidava mediante profundas transformações na estrutura institucional e financeira das políticas sociais, devida à aceleração dos processos de industrialização, urbanização e da transformação da estrutura social brasileira. (PEREZ e PASSONE, 2010, p. 662).

Era imprescindível que os indivíduos se apropriassem do instrumental e de mecanismos básicos para fazer valer os seus direitos, tendo na educação o seu principal veículo, uma vez que a educação é considerada um dos principais instrumentos de formação da cidadania.

Partindo de Herzer, é legítimo afirmar que por meio das suas vivências na FEBEM, construiu laços familiares com as outras menores que ali estavam. A instituição foi quem ocupou o lugar de sua família durante sua adolescência e foi ali que ela teve a possibilidade de socialização e educação. Na instituição ela vivia todas as experiências que poderiam também ser vivenciadas junto com seus parentes consanguíneos, desde o momento em que acordava, das refeições, do banho, dos afazeres diários, até a hora de dormir ela estava estabelecendo relações afetivas, cumprindo regras, se relacionando, como também é próprio da família, no trecho a seguir Hezer narra como era o momento das refeições: 


\section{Intrianianus RB;

\section{Volume, 14, n.1, ano, 2018}

Antes de todas as refeições, eram formadas três filas, em frente à portado refeitório; depois que todas permaneciam em silêncio, o inspetor nos mandava rezar. Nossa reza era apenas uma frase que dizia: "Abençoai, Senhor, esta refeição que vamos tomar”. Após a reza, entravamos de três em três para a refeição. (HERZER, 1983, p. 49).

A educação destinada à formação profissional era oferecida em tempo integral, no entanto, Herzer expõe que o desinteresse por parte das internas, era geral:

Sei que pelo horário escolar das menores, tem-se a impressão de que esses cursos profissionalizantes dão algum progresso às mesmas; mas isso não é verdade. São cursos tais como: arte culinária, corte e costura, couro, tecelagem, cabeleireiro; as meninas revezam de cursos de seis em seis meses e, no final de cada um, seria até bom se perguntassem a cada uma, se aprendeu algo no curso que acabou de fazer. (HERZER, 1983, p. 50).

Jacquet (2009), diz que as práticas das famílias também são determinadas por relações de gênero, mediante ao relato de Herzer onde ela cita os cursos oferecidos pela FEBEM para formação das internas, podemos perceber que não se destinam as meninas uma formação técnica ou científica, mas sim uma formação determinista, sem dinamismo, sem ambição e senso de esforço, e destinada aos cuidados do lar.

Vale ressaltar que o sucesso da Herzer em suas conquistas mediante a educação vai contra a análise da Sociologia da Educação clássica, que vê e analisa a criança no viés da escolarização, na sua ocupação de aluno. Se pensarmos a autora no enfoque dessa análise, ela não teria condições para escrever e até publicar um livro, no entanto, ela foge das estatísticas e da taxação de que todo menor da FEBEM está condenado a viver na marginalidade. Analisar a infância dessa forma é um erro, pois, investigar a criança sem investigar seus diferentes contextos sociais, culturais, econômicos e individuais, é mais uma forma de institucionalizar e estigmatizar a criança e a infância, como fez a FEBEM durante tanto tempo.

Desta forma, os processos de socialização, educação e instituições sociais, não permite uma análise monológica, uma vez que tais categorias não constroem um conjunto de referências estáveis, tanto no âmbito do conhecimento, como em relação aos modelos culturais.

\section{Considerações finais:}




\section{Volume, 14, n.1, ano, 2018}

A literatura foi usada pelas autoras como arma de defesa contra a violência, a fome, as injustiças sociais, os preconceitos, nesse sentido, Antonio Candido (1995) em seu texto $O$ direito à literatura afirma que "[...] a literatura confirma e nega, propõe e denuncia, apoia e combate, fornecendo possibilidades de vivermos dialeticamente os problemas". (CANDIDO, 1995, p. 177), sendo assim, o autor defende que o acesso a literatura é um dos direitos humanos fundamentais do indivíduo e nega que esse acesso seja exclusivo das elites.

Carolina Maria de Jesus e Sandra Mara Herzer, duas mulheres pobres, sem acesso adequado aos sistemas educacionais reconhecidos pela sociedade, fizeram da literatura uma forma para manifestar suas emoções e expressar suas visões de mundo, trazendo em seus relatos as vozes de tantas outras pessoas que vivenciavam as mesmas condições de vida relatadas por elas, fato esse que nos possibilitou realizar um resgate analítico sobre o contexto histórico vivenciado pelas autoras.

Ao nos atentamos sobre o conceito de Literatura Marginal, e como a questão da cidadania, aparece nestas obras percebemos que no caso de Carolina, para além da luta por cidadania, contra a fome, preconceito e racismo lhe foi negado o direito de ser reconhecida autenticamente como escritora, o que pode ser observado pelo subtítulo do seu livro "o diário de uma favelada", ela foi considerada como a favelada que escreveu a vida dos favelados, e não como a escritora que contou sua história de forma literária. Ocupando o lugar de mulher, negra e pobre não agradou a sociedade que julga que quem está apto a escrever é o homem branco da elite.

Herzer desiste de viver dois meses antes de seu livro ser publicado, e se joga do viaduto 13 de maio, na capital Paulista; existem poucos estudos no meio científico à respeito de seu livro, porém, se fosse viva, a autora poderia facilmente trilhar o mesmo caminho que Carolina trilhou, e conseguir ter uma grande visibilidade, apenas em sua primeira obra, já que também não se encaixava nos padrões exigidos pelos sujeitos sociais investidos de autoridade para definir o que é e o que não é literatura, e ex-interna da FEBEM, segundo a visão corrente, só podia falar sobre a FEBEM, assunto que conhecia muito bem. Como se o fato de ter vivido na instituição empobrecesse-lhe a escrita, comprometendo sua ficcionalidade.

\section{REFERÊECIAS:}

ABRAMOWICZ, Anete. A pesquisa com crianças em infâncias e a sociologia da infância. In: 


\section{Intrianianus REF LEctilonis \\ REVISTA ELETRONICA \\ GRADUACSAO/POS-GRADUACAO EM EDUCACAO \\ UFG/REJ}

\section{Volume, 14, n.1, ano, 2018}

FARIA, Ana Lúcia Goulart de; FINCO, Daniela (Org.). Sociologia da Infância no Brasil. Campinas, SP: Autores Associados, 2011 (Coleção Polêmicas do nosso tempo).

CANDIDO, Antonio. O direito à literatura. In: Vários escritos. São Paulo: Duas Cidades, 1995.

CARNEIRO, Vinícius Gonçalves. Reflexões quanto à literatura marginal brasileira: comparando Ferréz a sua tradição literária. In: Estud. Lit. Bras. Contemp., Brasília , n. 50, p. 254-276, Apr. 2017 . Disponível em: http://dx.doi.org/10.1590/2316-40185017 .

Acesso em: 06/ Ago/2017.

CARVALHAL, Thiago José Moraes. NO SENTIDO (de) DA(r) MARGEM (à literatura e à música): rap, cumbiavillera, Literatura Marginal e Realismo Atolondrado.2014. Dissertação (Mestrado em Letras Neolatinas) - Programa de Pós-Graduação em Letras Neolatinas, Universidade Federal do Rio de Janeiro, Rio de Janeiro. Disponível em:http://www.letras.ufrj.br/pgneolatinas/media/bancoteses/thiagocarvalhalmestrado.pdf.

Acesso em: 03/ago/2017.

CORONEL, Luciana Paiva. A censura ao direito de sonhar em Quarto de despejo, de Carolina Maria de Jesus. Estud. Lit. Bras. Contemp., Brasília , n. 44, p. 271288, Dec. 2014 Disponível em: http://www.scielo.br/scielo.php?script=sci arttext\&pid=S2316$40182014000200013 \& \operatorname{lng}=$ en\&nrm=iso . Acesso em: 24/Abr/2017.

DEL PRIORE, M. (Org.) História da criança no Brasil. São Paulo: Contexto, 1998.

HERZER. Sandra Mara. A Queda para o Alto. Editora Vozes: Petrópolis, 1982.

JACQUET, Christine. Socialização das crianças e diversificação dos arranjos familiares. Salvador: EDUFBA, 2009. Disponível em: http://books.scielo.org/id/3w52w/pdf/mendonca9788523208974-14.pdf

Acesso em: 07/ago/2016.

JESUS, Carolina. M. de. Quarto de despejo: diário de uma favelada. São Paulo: Livraria Francisco Alves, 1993.

KOSMINSKY, Ethel V. Internatos: os filhos do estado padrasto. In: MARTINS, José de Souza. (org.). O massacre dos inocentes: a criança sem infância no Brasil. São Paulo: Hucitec, 1993. P. 155-179.

Londoño, Fernando Torres. "A origem do conceito menor". In: PRIORI, Mary Dey. (org.). História das crianças no Brasil. São Paulo: Contexto, 1999, p. 129-145.

MIRANDA, Fernanda Rodrigues de. Os caminhos literários de Carolina Maria de Jesus: experiência marginal e construção estética. 2013. 153f. Dissertação (Mestrado em Estudos Comparados de Literatura em Língua Portuguesa) - Departamento de Letras Clássicas e vernáculas da Faculdade de Filosofia, Letras e Ciências Humanas da Universidade de São 


\section{Hetrialinus REF LEGTIOAIS

Volume, 14, n.1, ano, 2018

Paulo, São Paulo.

MUZART, Zahidé Lupiaacci. “A questão do cânone”. Anuário de Literatura, Santa Catarina, n. 3, 1995, p. 85-94.

NOGUEIRA, Maria Alice. Relação família-escola: novo objeto na sociologia da educação. Paidéia (Ribeirão Preto), Ribeirão Preto, v. 8, n. 14-15, p. 91-103, Aug. 1998.

PERES, E. P. Poética de resíduos. Revista Fapesp Ed. 231. Maio/2015. Pp. 78-81. Disponível em: http://revistapesquisa.fapesp.br/2015/06/24/poetica-da-diaspora/ Acesso em: 18/mai/2015.

PEREZ, José Roberto Rus; PASSONE, Eric Ferdinando. Políticas sociais de atendimento às criancas e aos adolescentes no Brasil. Cadernos de pesquisa. 2010. Vol. 40. Disponível em: http://www.scielo.br/pdf/cp/v40n140/a1740140.pdf. Acesso em: 07/ago/2016

SOUZA, Germana Henriques Pereira de. Carolina Maria de Jesus: o estranho diário da escritora vira lata. Vinhedo: Editora Horizonte, 2012.

SOARES, Mei Hua. A literatura marginal-periférica na escola. Dissertação (Mestrado em Educação) - Faculdade de Educação, Universidade de São Paulo. São Paulo 2009.

SUPLICY, Eduardo. Entrevista concedida ao Promenino Fundação Telefônica [jun. 2015]. Entrevistador: Tânia Carlos. São Paulo, 2015.

Van-Zanten, A. H. (1988). Les families face à l'école - rapports institutionnels et relations sociales. Em P. Durning (Org) Education familiale: un panorama des recherches internationales. Paris: MIRE/Matrice. pp. 185-207 